\title{
Primary Imaging Test for Suspected Traumatic Thoracolumbar Spine Injury: 2017 Guidelines by the Korean Society of Radiology and National Evidence-Based Healthcare Collaborating Agency
}

\author{
Guen Young Lee, MD, PhD ${ }^{1}$, Ji Young Hwang, MD, PhD ${ }^{2}$, Na Ra Kim, MD, PhD ${ }^{3}$, Yusuhn Kang, MD, PhD ${ }^{4}$, \\ Miyoung Choi, MPH, PhD ${ }^{5}$, Jimin Kim, $\mathrm{MPH}^{5}$, Eun Ju Ha, MD, PhD ${ }^{6}$, Jung Hwan Baek, MD, PhD ${ }^{7}$ \\ ${ }^{1}$ Department of Radiology, Chung-Ang University Hospital, Seoul, Korea; ${ }^{2}$ Department of Radiology, Ewha Womans University Seoul Hospital, \\ Seoul, Korea; ${ }^{3}$ Department of Radiology, Gunkuk University Hostpial, Seoul, Korea; ${ }^{4}$ Department of Radiology, Seoul National University Bundang \\ Hospital, Seongnam, Korea; ${ }^{5}$ Division for Healthcare Technology Assessment Research, National Evidence-Based Healthcare Collaborating Agency, \\ Seoul, Korea; ${ }^{6}$ Department of Radiology, Ajou University School of Medicine, Suwon, Korea; ${ }^{7}$ Department of Radiology and Research Institute of \\ Radiology, University of Ulsan College of Medicine, Seoul, Korea
}

The Korean Society of Radiology and the National Evidence-based Healthcare Collaborating Agency developed a primary imaging test for suspected traumatic thoracolumbar spine injury. This guideline was developed using an adaptation process involving collaboration between the development committee and the working group. The development committee, consisting of research methodology experts, established the overall plan and provided support on research methodology. The working group, composed of radiologists with expertise in musculoskeletal imaging, wrote the recommendation. The guidelines recommend that thoracolumbar spine computed tomography without intravenous contrast enhancement be the first-line imaging modality for diagnosing traumatic thoracolumbar spine injury in adults.

Keywords: Spine; Injury; Trauma; Guideline; Radiography; Computed tomography; Magnetic resonance imaging

\section{INTRODUCTION}

The thoracolumbar segment is the most commonly injured part of the spine. Vertebral fractures usually develop at T11L2 (50-60\%), most frequently caused by high-energy blunt trauma and in men between 20 and 40 years of age $(1,2)$. Neurological injury complicates $20-36 \%$ of thoracolumbar fractures $(3,4)$.
Classically, plain radiographic evaluation including anteroposterior and lateral radiographs is carried out first for assessment of the thoracolumbar spine, with advantages of low cost and availability (5). However, about $25 \%$ of burst fractures are misdiagnosed as simple compression fractures when only plain radiography is used (6). Computed tomography (CT) depicts more detailed injury characteristics, such as the type of fracture or the extent

Received November 12, 2018; accepted after revision November 12, 2018.

This study was supported by the Research Program funded by the Korea Centers for Disease Control and Prevention (fund code: 2017E3600100). The authors gratefully acknowledge the Korean Society of Spine Surgery, the Korean Spinal Neurosurgery Society, the Korean Orthopaedic Association, the Korean Neurosurgical Society, and the Korean Society of Emergency Medicine for external review for the final recommendation document.

This work was co-investigated by the National Evidence-based Collaborating Agency and the Korean Society of Radiology (Research Number: NECA-S-17-005).

Corresponding author: Ji Young Hwang, MD, PhD, Department of Radiology, Ewha Womans University Seoul Hospital, 260 Gonghangdaero, Gangseo-gu, Seoul 07804, Korea.

- Tel: (822) 6986-3727 • Fax: (822) 2650-5302 • E-mail: mshjy@ewha.ac.kr

This is an Open Access article distributed under the terms of the Creative Commons Attribution Non-Commercial License (https:// creativecommons.org/licenses/by-nc/4.0) which permits unrestricted non-commercial use, distribution, and reproduction in any medium, provided the original work is properly cited. 
of central canal compromise $(7,8)$. Magnetic resonance imaging (MRI) clearly demonstrates soft tissue injuriesfor example, those involving ligaments (9) as well as bone marrow (10)-without radiation exposure. MRI may be performed immediately and is particularly beneficial for in patients with neurologic deficits. However, MRI requires earnest patient cooperation and is associated with long scan times and high costs.

The need for standardized, evidence-based clinical guidelines, including recommendations for initial screening imaging, was proposed for the diagnosis of traumatic thoracolumbar spine injury in adults. The Korean Society of Radiology (KSR) and the National Evidence-based Healthcare Collaborating Agency (NECA) organized the development committee and the working group to develop these guidelines (11).

\section{Development of Korean Clinical Imaging Guidelines for Traumatic Thoracolumbar Spine Injury}

\section{Committee Composition}

The guideline development process was performed via a collaboration of the NECA and the KSR. The NECA is the national research agency, which was inaugurated to provide evidence-based information about medical devices, medicines, and health technology through objective and reliable analysis. The development committee and the working group were mobilized for guideline development. The development committee was composed of medical imaging experts, research methodology specialists, and clinical guideline specialists who supported the overall planning and research methodology. They published an article detailing the methods involved in the guideline adaptation process for diagnostic imaging (11). The working group was composed of expert members of the Korean Society of Musculoskeletal Radiology (KSMR). The KSMR is an organization of radiologists in Korea and a subspecialty society of the KSR, which is primarily involved in the diagnosis and non-surgical treatment of musculoskeletal disorders.

\section{Guideline Adaptation Process}

The guideline development process was performed using an adaptation methodology for Korean Clinical Imaging Guidelines (K-CIGs) established by the development committee (11).

\section{Defining the Key Question}

The key question selected by the working group was reviewed by the development committee and a consensus group composed of clinical experts who were end-users and referrers-individuals performing clinical imaging tests. The key question was:

What is the primary imaging test for diagnosis in patients with suspected traumatic thoracolumbar spine injury?

\section{Guideline Search}

A systematic guideline search was performed using international databases, including 0vid-MEDLINE, OvidEMBASE, National Guideline Clearinghouse, Guideline International Network, and major Korean databases, including KoreaMed, KMBASE, and Korean Medical Guidelines and information published up to March 2017. Additionally, the websites of major academic societies and institutions were searched, and hand searching was carried out.

\section{Selection of Searched Guidelines}

Guideline selection was performed independently based on predefined inclusion and exclusion criteria, in pairs. Articles reporting the conduct and findings of 570 studies addressed the key question, and 545 studies remained after exclusion of duplicates. Fourteen articles remained after screening the titles and abstracts, and one article was added by hand searching. Among these 15 articles, 12 articles were excluded, and three guidelines were selected after on full-text review (Fig. 1).

\section{Quality Appraisal of the Guidelines}

The final selected guidelines underwent a quality appraisal process using the Korean Appraisal of Guidelines for Research \& Evaluation II tool (12), developed by the guideline development committee (Table 1). Guidelines with a score less than 50 in the "Rigor of Development" domain were not recommended by the development committee. All three guidelines met this condition, and they were selected as relevant to the key question after the quality appraisal process.

\section{Grading the Level of Evidence and Drafting the Recommendation Document}

The working group members reviewed relevant literature supporting the recommendations stated in the final selected guidelines. Grading the level of evidence of each source of evidence was performed according to the evidence level 


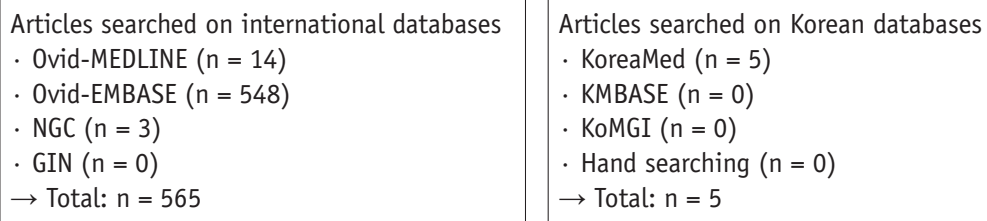

Fig. 1. Flow diagram of guideline selection (key question). GIN = Guideline International Network, KoMGI = Korean Medical Guidelines, $N G C=$ National Guideline Clearinghouse

criteria of the K-CIGs (11).

\section{Agreement of the Recommendation Grades}

The draft version of the recommendation document prepared by the working group was reviewed and discussed by the development committee. The final level of evidence and grade of recommendations were determined through consensus between the development committee and the working group, according to the criteria of the K-CIG (11).

\section{Finalizing the Recommendation Document}

The Delphi method was used for formal consensus. The consensus group was composed of clinical imaging experts, clinical imaging guideline-related academic societies (endusers), and research methodology experts. The agreement level for recommendation, recommendation grading, and evidence level ranged from strongly disagree (level 1 ) to strongly agree (level 9). After two rounds of assessment, a consensus was reached.

Seventeen experts from the consensus group answered, and the results of the Delphi were as follows: mean degree of agreement on recommendation was 7.2 (standard deviation: 1.5) in the first survey and 7.4 (standard deviation: 1.0) in the second survey. The coefficient variation decreased from 0.2 to 0.1 which means the extent of agreement between panels increased.

\section{External Review and Approval of Clinical Guidelines}

Final recommendations were reviewed by clinical experts. Feedback and modification were reflected in the documents. K-CIG grades were submitted to the Korean Academy of Medical Sciences for approval and dissemination. Final approval was determined on March 13, 2018.

\section{Recommendation}

\section{Key Question: What Is the Primary Imaging Test for Diagnosis in Patients with Suspected Traumatic Thoracolumbar Spine Injury?}

\section{Recommendation}

We recommend thoracolumbar spine $\mathrm{CT}$ without intravenous contrast enhancement for the diagnosis of traumatic thoracolumbar spine injury (Recommendation grade B, Evidence level II). 


\section{Evidence Summary}

After reviewing several guidelines for the diagnosis of thoracolumbar spine injury in adults with trauma, three guidelines were selected (13-15). Previous studies recommended an imaging test to confirm thoracolumbar

Table 1. Recommendations Matrix of Existing Guidelines (Key Question)

\begin{tabular}{lccc}
\hline $\begin{array}{c}\text { Source Guidelines } \\
\text { (Publication Year) }\end{array}$ & ACR Appropriateness Criteria & ACR Appropriateness Criteria; & Spinal Injury: Assessment and Initial \\
Myelopathy (2016) & Suspected Spinal Trauma (2012) & Management (2016) \\
\hline
\end{tabular}

AGREE II (domain 3.

Rigor of Development)

1. CT is usually preferred first test in suspected spinal trauma

2. MRI is usually preferred first test in nontraumatic myelopathy. Imaging should be limited to appropriate spinal levels by clinical judgment and physical examination

3. Gadolinium contrast administration is preferred in oncology, infection, inflammation, and suspected vascular causes of myelopathy

4. Spinal angiography (invasive and/or computed tomography angiography/magnetic resonance angiography)

Recommendation

of selected patients with
suspected treatable causes of
vascular myelopathy
5. In oncologic patients and
those in whom infectious
disease is likely, additional
imaging tests may be helpful
in determining source
and extent of compressive
components; however, MRI
remains first-line imaging test
for evaluation of myelopathic
symptoms
6. No high-quality evidence
supports use of discography,
thermography, epidural
venography, ultrasound,
or cerebrospinal fluid flow
studies in evaluation of
myelopathy

Grading of recommendation

69

81

1. Once decision is made to scan patient, entire spine should be examined, owing to high incidence of noncontiguous multiple injuries

2. Thoracic and lumbar CT examinations derived from thoracic abdomen-pelvic CT examinations may be used instead of primary spine imaging

3. Radiography has limited use in adults and should be used primarily for resolving nondiagnostic CT studies due to motion artifacts

4. Flexion-extension radiography is not useful in acute injury period because of muscle spasm

5. MRI is procedure of choice for evaluating patients with suspected spinal cord injury or for cord compression, as well as for determining integrity of spinal ligaments, particularly in obtunded patients

6. Multi-detector CT, however, has been shown in literature to be as effective as MRI for determining spinal stability. Spine surgeons may prefer to use MRI

7. Dynamic fluoroscopy should not be used to evaluate for ligamentous injury in obtunded patients
1. Imaging for spinal injury should be performed urgently, and images should be interpreted immediately by healthcare professional with training and skills in this area

2. Perform radiography as firstline investigation for people with suspected spinal column injury without abnormal neurological signs or symptoms in thoracic or lumbosacral regions (T1-L3)

3. Perform CT if radiography is abnormal or there are clinical signs or symptoms of spinal column injury

4. If new spinal column fracture is confirmed, image rest of spinal column

5. Use whole-body CT (consisting of vertex-to-toes scanogram, followed by CT from vertex to mid-thigh) in adults (16 years or older) with blunt major trauma and suspected multiple injuries. Patients should not be repositioned during whole-body CT

6. Use clinical findings and scanogram to direct CT of limbs in adults (16 years or older) with limb trauma

7. If person with suspected spinal column injury is undergoing wholebody CT, carry out multiplanar reformatting to show all of thoracic and lumbosacral regions with sagittal and coronal reformats

8. Do not routinely use whole-body CT to image children (under 16 years). Use clinical judgement to limit CT to body areas where assessment is needed

$\mathrm{ACR}=$ American College of Radiology, AGREE $=$ Appraisal of Guidelines for Research \& Evaluation 
spine injury when any of the following are present: localizing signs of thoracolumbar injury, a neurologic deficit, cervical spine fracture, Glasgow Coma Scale score less than 15 points, major distracting injury, or a history of alcohol or drug addiction (16-18). CT has been reported to be more accurate than plain radiography in the diagnosis of thoracolumbar spine injury $(8,19-25)$. The sensitivity and specificity of plain radiography for the depiction of thoracolumbar fracture have been estimated to be $49-82 \%$ and $55-93 \%$ compared to CT, respectively $(6-8,19,20$, 24, 26-31). Furthermore, reformatted image using axial chest $\mathrm{CT}$ or abdominopelvic CT may be helpful to assess thoracolumbar spine injury $(7,8,21,24,30-36)$. Because coincident fractures of multiple spinal levels are relatively common, multi-detector CT (MDCT) may be recommended as the first-choice imaging modality $(8,22-24,35-38)$. Meanwhile, isolated unstable ligamentous injury without thoracolumbar fracture is rare; thus, additional MRI evaluation is not usually recommended when CT findings are normal (39-41). CT demonstrated $0-88 \%$ sensitivity and 94-100\% specificity for diagnosing of soft tissue injury, except spinal cord injury, compared with MRI (42-45).

\section{Considerations for Recommendation}

\section{Harm and Benefit}

MDCT has a relatively high risk of radiation exposure than plain radiography when used as an initial screening imaging test for the diagnosis of thoracolumbar spine injury. If chest CT or abdominopelvic CT are conducted, reformatted images may be used for assessment of thoracolumbar spine injury without additional thoracolumbar spine CT.

\section{Acceptability and Applicability}

CT is available in the majority of hospitals in Korea, and its benefits include short scanning times, and no requirements for IV contrast administration or keeping patients nil per os. As a result of the evaluation of domestic acceptability and applicability of these three guidelines, it was concluded that the acceptability and applicability of thoracolumbar spine CT without IV contrast enhancement are reasonable for diagnosing thoracolumbar spine injury.

\footnotetext{
Radiation Dose

Plain radiography:

Thoracolumbar spine CT:

Thoracolumbar spine MRI: 0
}

\section{SUMMARY}

This is the first evidence-based clinical imaging guideline document for the screening of thoracolumbar spine injury in Korea, and it was developed using an adaptation process. The primary recommendation is that thoracolumbar CT without IV contrast enhancement should be the first-line imaging modality for the diagnosing thoracolumbar spine injury in patients with suspected spinal trauma.

\section{Conflicts of Interest}

The authors have no potential conflicts of interest to disclose.

\author{
ORCID iDs \\ Ji Young Hwang \\ https://orcid.org/0000-0001-5848-3429 \\ Guen Young Lee \\ https://orcid.org/0000-0002-6906-5182
}

\section{REFERENCES}

1. Gertzbein SD. Scoliosis Research Society. Multicenter spine fracture study. Spine (Phila Pa 1976) 1992;17:528-540

2. Gertzbein SD, Khoury D, Bullington A, St John TA, Larson AI. Thoracic and lumbar fractures associated with skiing and snowboarding injuries according to the A0 comprehensive classification. Am J Sports Med 2012;40:1750-1754

3. Magerl F, Aebi M, Gertzbein SD, Harms J, Nazarian S. A comprehensive classification of thoracic and lumbar injuries. Eur Spine J 1994;3:184-201

4. Kraemer WJ, Schemitsch EH, Lever J, McBroom RJ, McKee MD, Waddell JP. Functional outcome of thoracolumbar burst fractures without neurological deficit. J Orthop Trauma 1996;10:541-544

5. Moutinho R, Tyrrell P, Cassar-Pullicino VN. Emergency and trauma imaging of the thoracolumbar spine. Semin Musculoskelet Radiol 2017;21:199-209

6. Ballock RT, Mackersie R, Abitbol JJ, Cervilla V, Resnick D, Garfin SR. Can burst fractures be predicted from plain radiographs? J Bone Joint Surg Br 1992;74:147-150

7. Hauser CJ, Visvikis G, Hinrichs C, Eber CD, Cho K, Lavery RF, et al. Prospective validation of computed tomographic screening of the thoracolumbar spine in trauma. J Trauma 2003;55:228234; discussion 234-235

8. Wintermark M, Mouhsine E, Theumann N, Mordasini P, van Melle G, Leyvraz PF, et al. Thoracolumbar spine fractures in patients who have sustained severe trauma: depiction with multi-detector row CT. Radiology 2003;227:681-689

9. Pizones J, Zúñiga L, Sánchez-Mariscal F, Alvarez P, Gómez-Rice A, Izquierdo E. MRI study of post-traumatic incompetence 
of posterior ligamentous complex: importance of the supraspinous ligament. Prospective study of 74 traumatic fractures. Eur Spine J 2012;21:2222-2231

10. Pizones J, Izquierdo E, Alvarez P, Sánchez-Mariscal F, Zúñiga $L$, Chimeno $P$, et al. Impact of magnetic resonance imaging on decision making for thoracolumbar traumatic fracture diagnosis and treatment. Eur Spine J 2011;20 Suppl 3:390-396

11. Choi SJ, Jeong WK, Jo AJ, Choi JA, Kim MJ, Lee M, et al. Methodology for developing evidence-based clinical imaging guidelines: joint recommendations by Korean Society of Radiology and National Evidence-based Healthcare Collaborating Agency. Korean J Radiol 2017;18:208-216

12. Steering Committee for Clinical Practice Guideline. Korean appraisal of guidelines for research \& evaluation II. The AGREE next steps consortium, 2009. Available at: http:// www.agreetrust.org/wp-content/uploads/2013/06/AGREE_II_ Korean.pdf. Accessed March 1, 2017

13. Roth CJ, Angevine PD, Aulino JM, Berger KL, Choudhri AF, Fries IB, et al. ACR appropriateness criteria myelopathy. J Am Coll Radiol 2016;13:38-44

14. Daffner RH, Hackney DB. ACR Appropriateness Criteria ${ }^{\circledR}$ on suspected spine trauma. J Am Coll Radiol 2007;4:762-775

15. National Clinical Guideline Centre (UK). Spinal injury: assessment and initial management. London: National Institute for Health and Care Excellence, 2016

16. Chang CH, Holmes JF, Mower WR, Panacek EA. Distracting injuries in patients with vertebral injuries. J Emerg Med 2005;28:147-152

17. Dai LY, Yao WF, Cui YM, Zhou Q. Thoracolumbar fractures in patients with multiple injuries: diagnosis and treatment-a review of 147 cases. J Trauma 2004;56:348-355

18. Hsu JM, Joseph T, Ellis AM. Thoracolumbar fracture in blunt trauma patients: guidelines for diagnosis and imaging. Injury 2003;34:426-433

19. Brown CV, Antevil JL, Sise MJ, Sack DI. Spiral computed tomography for the diagnosis of cervical, thoracic, and lumbar spine fractures: its time has come. J Trauma 2005;58:890895; discussion 895-896

20. Berry GE, Adams S, Harris MB, Boles CA, McKernan MG, Collinson $F$, et al. Are plain radiographs of the spine necessary during evaluation after blunt trauma? Accuracy of screening torso computed tomography in thoracic/lumbar spine fracture diagnosis. J Trauma 2005;59:1410-1413; discussion 1413

21. Brandt MM, Wahl WL, Yeom K, Kazerooni E, Wang SC. Computed tomographic scanning reduces cost and time of complete spine evaluation. J Trauma 2004;56:1022-1026; discussion 1026-1028

22. Herzog C, Ahle H, Mack MG, Maier B, Schwarz W, Zangos $S$, et al. Traumatic injuries of the pelvis and thoracic and lumbar spine: does thin-slice multidetector-row CT increase diagnostic accuracy? Eur Radiol 2004;14:1751-1760

23. Lucey BC, Stuhlfaut JW, Hochberg AR, Varghese JC, Soto JA. Evaluation of blunt abdominal trauma using PACS-based 2D and 3D MDCT reformations of the lumbar spine and pelvis. AJR
Am J Roentgenol 2005;185:1435-1440

24. Sheridan R, Peralta R, Rhea J, Ptak T, Novelline R. Reformatted visceral protocol helical computed tomographic scanning allows conventional radiographs of the thoracic and lumbar spine to be eliminated in the evaluation of blunt trauma patients. J Trauma 2003;55:665-669

25. van Beek EJ, Been HD, Ponsen KK, Maas M. Upper thoracic spinal fractures in trauma patients - a diagnostic pitfall. Injury 2000;31:219-223

26. Dai LY, Wang XY, Jiang LS, Jiang SD, Xu HZ. Plain radiography versus computed tomography scans in the diagnosis and management of thoracolumbar burst fractures. Spine (Phila Pa 1976) 2008;33:E548-E552

27. Karul M, Bannas P, Schoennagel BP, Hoffmann A, Wedegaertner $U$, Adam $G$, et al. Fractures of the thoracic spine in patients with minor trauma: comparison of diagnostic accuracy and dose of biplane radiography and MDCT. Eur J Radiol 2013;82:1273-1277

28. Campbell SE, Phillips CD, Dubovsky E, Cail WS, Omary RA. The value of CT in determining potential instability of simple wedge-compression fractures of the lumbar spine. AJNR Am J Neuroradiol 1995;16:1385-1392

29. Krueger MA, Green DA, Hoyt D, Garfin SR. Overlooked spine injuries associated with lumbar transverse process fractures. Clin Orthop Relat Res 1996;(327):191-195

30. Rhea JT, Sheridan RL, Mullins ME, Novelline RA. Can chest and abdominal trauma CT eliminate the need for plain films of the spine? - Experience with 329 multiple trauma patients. Emergency Radiology 2001;8:99-104

31. Rhee PM, Bridgeman A, Acosta JA, Kennedy S, Wang DS, Sarveswaran J, et al. Lumbar fractures in adult blunt trauma: axial and single-slice helical abdominal and pelvic computed tomographic scans versus portable plain films. J Trauma 2002;53:663-667; discussion 667

32. Gestring ML, Gracias VH, Feliciano MA, Reilly PM, Shapiro MB, Johnson JW, et al. Evaluation of the lower spine after blunt trauma using abdominal computed tomographic scanning supplemented with lateral scanograms. J Trauma 2002;53:9-14

33. Inaba K, Munera F, McKenney M, Schulman C, de Moya M, Rivas $L$, et al. Visceral torso computed tomography for clearance of the thoracolumbar spine in trauma: a review of the literature. J Trauma 2006;60:915-920

34. Salim A, Sangthong B, Martin M, Brown C, Plurad D, Demetriades $D$. Whole body imaging in blunt multisystem trauma patients without obvious signs of injury: results of a prospective study. Arch Surg 2006;141:468-473; discussion 473-475

35. Mancini DJ, Burchard KW, Pekala JS. Optimal thoracic and lumbar spine imaging for trauma: are thoracic and lumbar spine reformats always indicated? J Trauma 2010;69:119-121

36. Smith MW, Reed JD, Facco R, Hlaing T, McGee A, Hicks BM, et al. The reliability of nonreconstructed computerized tomographic scans of the abdomen and pelvis in detecting thoracolumbar spine injuries in blunt trauma patients with altered mental 
Primary Imaging Test for Suspected Traumatic Thoracolumbar Spine Injury

status. J Bone Joint Surg Am 2009;91:2342-2349

37. Daffner RH, Sciulli RL, Rodriguez A, Protetch J. Imaging for evaluation of suspected cervical spine trauma: a 2-year analysis. Injury 2006;37:652-658

38. Hogan GJ, Mirvis SE, Shanmuganathan K, Scalea TM. Exclusion of unstable cervical spine injury in obtunded patients with blunt trauma: is MR imaging needed when multi-detector row CT findings are normal? Radiology 2005;237:106-113

39. Benzel EC, Hart BL, Ball PA, Baldwin NG, Orrison WW, Espinosa MC. Magnetic resonance imaging for the evaluation of patients with occult cervical spine injury. J Neurosurg 1996;85:824-829

40. Davis SJ, Khangure MS. A review of magnetic resonance imaging in spinal trauma. Australas Radiol 1994;38:241-253

41. O’Beirne J, Cassidy N, Raza K, Walsh M, Stack J, Murray P.
Role of magnetic resonance imaging in the assessment of spinal injuries. Injury 1993;24:149-154

42. Silberstein M, Tress BM, Hennessy 0. A comparison between M.R.I. and C.T. in acute spinal trauma. Australas Radiol 1992;36:192-197

43. Tracy PT, Wright RM, Hanigan WC. Magnetic resonance imaging of spinal injury. Spine (Phila Pa 1976) 1989;14:292-301

44. Pizones J, Sánchez-Mariscal F, Zúñiga L, Álvarez P, Izquierdo E. Prospective analysis of magnetic resonance imaging accuracy in diagnosing traumatic injuries of the posterior ligamentous complex of the thoracolumbar spine. Spine (Phila Pa 1976) 2013;38:745-751

45. Tarr RW, Drolshagen LF, Kerner TC, Allen JH, Partain CL, James AE Jr. MR imaging of recent spinal trauma. J Comput Assist Tomogr 1987;11:412-417 